\title{
Thoracic solitary pedunculated osteochondroma in a child: a case report
}

This article was published in the following Dove Press journal:

Orthopedic Research and Reviews

22 October 2013

Number of times this article has been viewed

\section{Zubair Wali' \\ Khalid I Khoshhal ${ }^{2}$ \\ 'Department of Orthopedic Surgery, King Fahd Hospital, Almadinah Almunawwarah, Saudi Arabia; ${ }^{2}$ Department of Orthopedic Surgery, College of Medicine, Taibah University, Almadinah Almunawwarah, \\ Saudi Arabia}

Correspondence: Zubair Wali

Unit I, 8647 Al-Der' Mosque, Almadinah Almunawwarah,

423।3-2359, Saudi Arabia

Tel +96650443 238I

Email znoorwali@gmail.com
Objective: This case report describes the rare presentation of a thoracic pedunculated osteochondroma in a child, arising from the lamina of the fourth thoracic vertebra.

Clinical features: A 7-year-old girl was referred for the evaluation of a swelling in her back. The patient was suffering from atraumatic, progressive painless back swelling, of approximately 2 years duration. The physical examination showed a healthy child, with a well-defined mass, about $4 \times 6 \mathrm{~cm}$, located around the midline of the upper thoracic spine. No clinical signs of hereditary multiple exostoses were detected. Plain radiographs and computerized tomography were suggestive of a pedunculated osteochondroma arising from the lamina of the fourth thoracic vertebra.

Intervention and outcome: The patient underwent surgical excision of the mass. The pathologist confirmed the diagnosis. Follow up for 2 years did not show any evidence of clinical or radiological recurrence.

Conclusion: The current report describes a rare case and the management of a solitary pedunculated osteochondroma arising from the lamina of the fourth thoracic vertebra in a child below the age of 10 years.

Keywords: benign tumors, hereditary multiple exostoses, spine column tumors, thoracic vertebra

\section{Introduction}

Osteochondromas are the most common benign bone and cartilage tumor, ${ }^{1,2}$ with a predilection for the metaphysis of long bones, and with the distal femur, the proximal tibia, and the proximal humerus being the most affected sites. ${ }^{3}$ Osteochondromas comprise almost $35 \%-40 \%$ of all primary benign bone tumors and $8 \%-9 \%$ of all bone tumors. ${ }^{3-6} \mathrm{~A}$ large number of these tumors are asymptomatic and may never be identified. Therefore, the incidence probably is higher than what is reported. ${ }^{3,7}$ Osteochondromas present as solitary lesions in around $85 \%$ of cases. The rest occur as part of hereditary multiple exostoses (HME), an autosomal dominant disease characterized by the formation of several benign cartilage-capped bone growths. ${ }^{1,8}$

In the context of a dysplastic disorder, osteochondromas can arise from any zone of endochondral bone formation. ${ }^{4}$ It is thought that they originate in a laterally displaced part of the epiphyseal cartilage, resulting in a dysplastic bony growth at the expense of progressive endochondral ossification. ${ }^{9}$

Osteochondromas usually begin their growth in early childhood and arrest after puberty, upon closure of the epiphyses. ${ }^{10}$ Malignant transformation of osteochondroma into a chondrosarcoma may occur in around $1 \%$ of solitary and $10 \%$ of HME. ${ }^{11}$ 

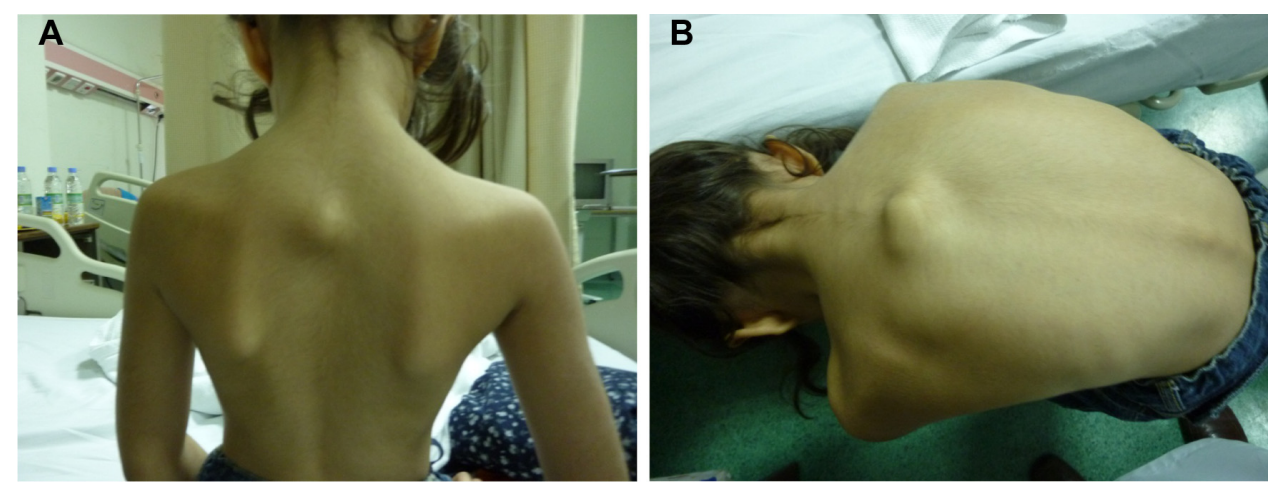

Figure I Clinical pictures, (A) standing and (B) bending forward, showing the presenting mass in the upper thoracic spine, near the midline.

Malignant transformation should be ruled out if the osteochondroma becomes painful or if it continues to grow after cessation of skeletal growth and if the thickness of the cartilaginous cap exceeds $2 \mathrm{~cm}$ in adults or $3 \mathrm{~cm}$ in children. ${ }^{1,12}$

Measurement of the thickness of the cap can be performed using ultrasound, computerized tomography (CT), or magnetic resonance imaging (MRI), but MRI scanning is the most accurate method. ${ }^{1,6,12}$

Asymptomatic lesions can be followed without intervention, whereas symptomatic ones are treated with surgical excision. ${ }^{1}$ Indications for excision of a solitary osteochondroma include pain, deformity, cosmesis, continued growth, suspected malignant transformation, and neurovascular compromise. , $^{2,3,12-14}$

There are two characteristic types of osteochondromas, pedunculated and sessile. The pedunculated type has a slender pedicle directed away from the growth plate. The sessile ones are broad based.

Solitary osteochondromas originating in the spine account for only $1 \%-4 \%$ of all osteochondromas., ${ }^{3,10,15-18}$ They most frequently involve the cervical spine, particularly $\mathrm{C} 1$ and C2. ${ }^{10,19,20}$ The next most frequently affected sites are the thoracic and the lumbar spine. ${ }^{4}$

We describe in this report, a solitary asymptomatic pedunculated osteochondroma arising from the lamina of the fourth thoracic (T4) vertebra, in a 7-year-old child. Although there is a good number of cases of osteochondromas reported in the literature, there have been very few spine osteochondroma cases reported below the age of 10 years. The exact number of pedunculated spine osteochondromas could not be identified, as many of the reported cases did not mention the type of osteochondroma.

\section{Case report}

A 7-year-old girl was referred to the orthopedic clinic for evaluation of a painless back swelling. The patient reported having the swelling, which was slowly progressing, for approximately 2 years. There was no history of trauma, night pain, or fever. The family was concerned about her cosmetic appearance, psychological effect, and some discomfort during sleep when she lay on her back.

Physical examination showed a healthy child with a well-defined mass about $4 \times 6 \mathrm{~cm}$ around the midline at the upper thoracic spine area. The mass was fixed, bony hard, nontender, deep to the skin and fascia, and nonadhered to the skin, and there were no signs of spinal deformity. (Figure 1). No other masses were palpable, and there was no clinical evidence of HME. The rest of the physical examination, including full neurovascular assessment, was normal.

Plain radiographs and CT scan (Figures 2 and 3) showed a protrusion of cortical and medullary bone relative to the cortical bone of the spinous process of the T4 vertebra, as well as zones of endochondral mineralization in the marrow underlying the osteochondroma. The medullary portion of the pedunculated osteochondroma was contiguous with the marrow of the adjacent bone.
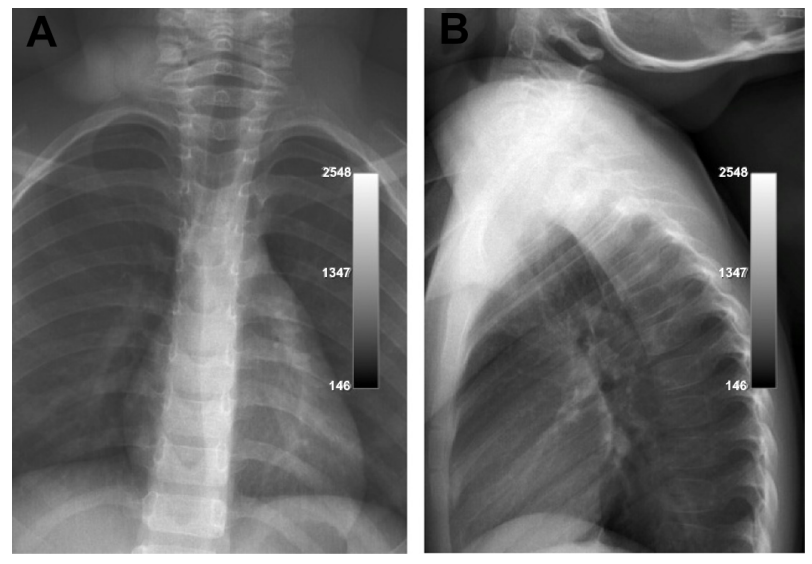

Figure 2 Plain radiographs, (A) posteroanterior and (B) lateral, showing an osteocartilagenous tumor arising from the upper thoracic vertebrae. 

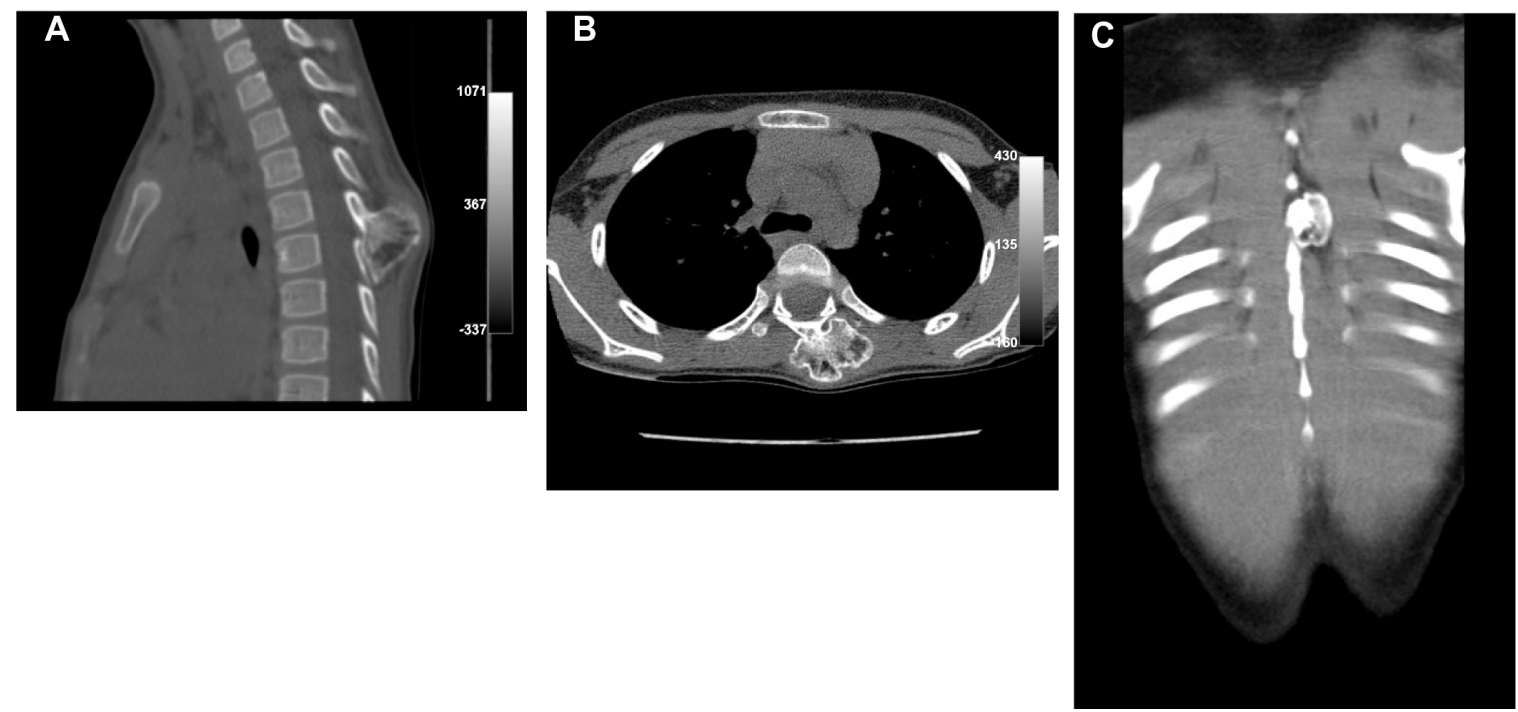

Figure 3 CT scan: (A) sagittal, (B) axial, and (C) coronal views. The CT showed the protrusion of cortical and medullary bone relative to the cortical bone of the spinous process of the T4 vertebra, as well as zones of endochondral mineralization in the marrow underlying the osteochondroma. The medullary portion of the pedunculated osteochondroma was contiguous with the marrow of the adjacent bone.

Abbreviation: $\mathrm{CT}$, computed tomography.

After discussing the treatment options with the parents, surgical excision was chosen and an informed consent was obtained.

The tumor was approached by a posterior midline incision and separated from the lamina and spinous process of the T4 vertebra and was completely removed, including the cartilaginous cap (en bloc excision), without injuring the lamina or the supraspinous ligament, interspinous ligament, or spinous process.

Pathologically (Figure 4), the lesion consisted of multiple irregular dome-shaped structures with a vague capsule, hyaline cartilage cap (measuring $3 \mathrm{~mm}$ ) that was continuous with bony trabeculae containing apparently normal marrow elements; a bony stalk with a cartilage cap features consistent with osteochondroma.

Follow up for 2 years did not show any signs of clinical or radiological recurrence (Figure 5).

\section{Discussion}

In the vast majority of cases, osteochondromas involve the long bones; their origin in the vertebral column is unusual, ${ }^{4,21,22}$ with an incidence of $1 \%-4 \%$. The commonest site of vertebral osteochondromas is at an eccentric position in the neural arch, with or without protrusion into the spinal canal. ${ }^{23}$ The intraspinal extension of an osteochondroma is uncommon. Thus, affected patients rarely present with neurological symptoms $(0.5 \%-1 \%){ }^{24}$ Spinal column osteochondromas usually arise dorsally or dorasolaterally, and the most common surgical treatment is a decompression laminectomy or hemilaminectomy, depending on the size of the lesion. ${ }^{25}$

Development in conjunction with HME is more common and has been thoroughly reviewed in previous articles. ${ }^{21,26-28}$ The average age of clinical manifestation, including all of spinal levels is, roughly, 30 years for solitary osteochondroma ${ }^{10,11}$
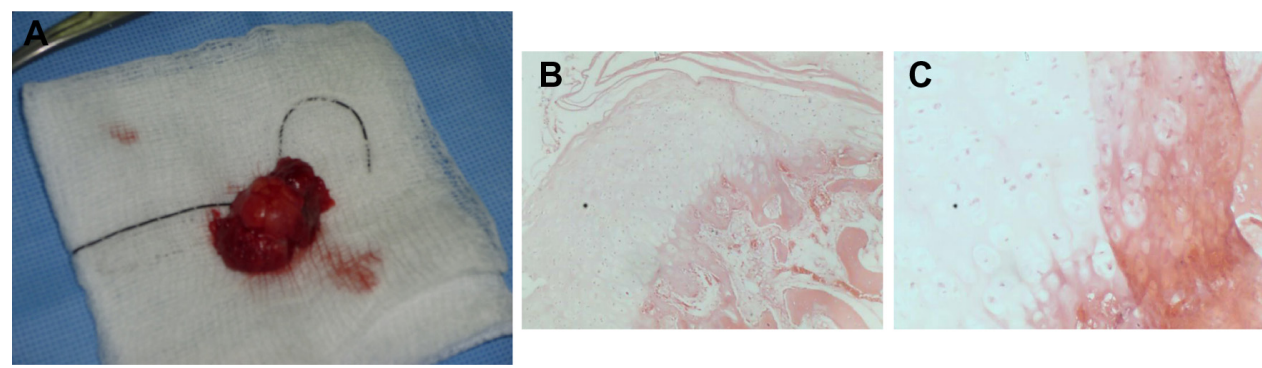

Figure 4 Pathology findings. The images show $(\mathbf{A})$ a photograph of the gross surgical specimen, (B) histopathology at $\times 10$ magnification; and $(\mathbf{C})$ histopathology at $\times 40$ magnification. The lesion consisted of multiple irregular dome-shaped structures with a vague capsule, hyaline cartilage cap (measuring $3 \mathrm{~mm}$ ) that was continuous with bony trabeculae containing apparently normal marrow elements; a bony stalk with a cartilage cap features consistent with osteochondroma. 

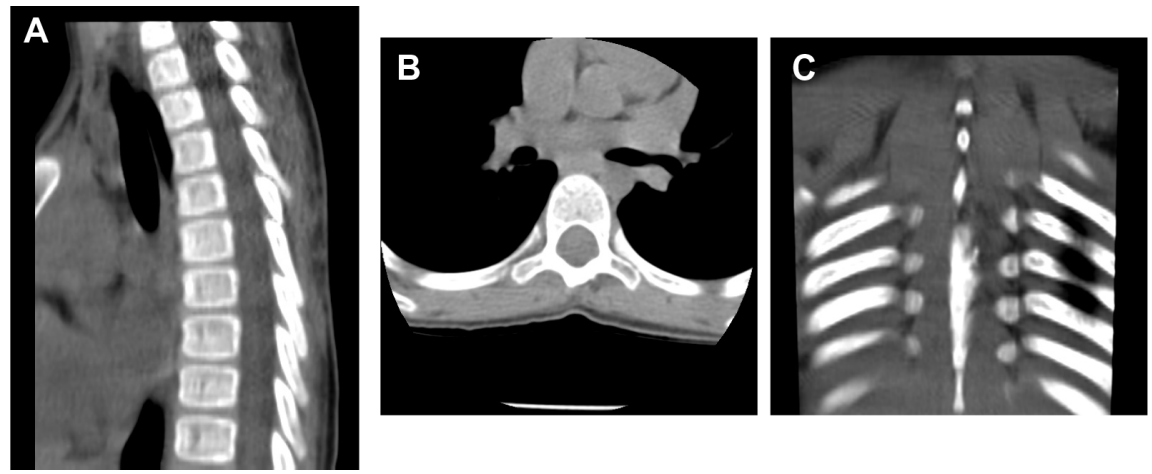

Figure 5 CT Scan, (A) sagittal, (B) axial, and (C) coronal views, at 2 years postoperation. The CT showed no signs of recurrence.

Abbreviation: CT, computed tomography.

and 20 years for HME. ${ }^{28}$ The pathophysiology of both HME and solitary osteochondroma remains unknown. ${ }^{28}$

In the reviews of osteochondroma reported by Albrecht et $\mathrm{al}^{10}$ and Roblot et al, ${ }^{11}$ the thoracic spine was the site of only $26 \%-28 \%$ of all spinal osteochondromas, despite comprising $40 \%$ of the vertebrae. Osteochondromas usually give rise to clinical symptoms during growth in the second or third decade of life. Four cases of spinal solitary osteochondroma below the age of 10 years were reported by Roblot et al, ${ }^{11}$ all in males and all in the cervical spine; one case of HME below the age of 10 years was reported, and it was also in the cervical spine. In the review articles of solitary thoracic osteochondromas reported by Brastianos et al, Roblot et al, and Khosla et al, only one case below the age of 10 years was reported. It was inseparable from the lamina (most likely, the sessile type)..$^{2,11,19}$ None of these papers reported the type of osteochondroma. Rao and Jakheria reported one case of a giant cervical pedunculated osteochondroma of a cervical spine in an 8-year-old girl with HME. ${ }^{29}$

The case in hand is atypical in that the tumor arose from the posterior element of the T4 vertebra as a pedunculated type, in a 7-year-old child. Surgical intervention was effective in completely resolving the patient's symptoms without injuring the vital anatomical structure of the spine and improved the psychological well-being of the patient.

In conclusion it is important to differentiate between a pedunculate and sessile type of osteochondroma in the spine because the sessile type is inseparable, and complete excision of the tumor requires removal of part of the lamina and spinous process, and the possible neurological complications are higher. The pedunculated type is separable and amenable to en bloc excision, without injuring the posterior spinal element.

\section{Disclosure}

The authors report no conflicts of interest in this work.

\section{References}

1. Arkader A, Dormans JP, Gaugler R, Davidson RS. Spontaneous regression of solitary osteochondroma: reconsidering our approach. Clin Orthop Relat Res. 2007;460:253-257.

2. Brastianos P, Pradilla G, McCarthy E, Gokaslan ZL. Solitary thoracic osteochondroma: case report and review of the literature. Neurosurgery. 2005;56(6):E1379.

3. Unni KK. Dahlin's Bone Tumors: General Aspects and Data on 11087 Cases. 5th ed. Philadelphia, PA: Lippincott-Raven; 1996.

4. Mexía MJA, Núñez EI, Garriga CS, Salinas RMS. Osteochondroma of the thoracic spine and scoliosis. Spine (Phila Pa 1976). 2001;26(9): 1082-1085.

5. Porter DE, Simpson AH. The neoplastic pathogenesis of solitary and multiple osteochondromas. J Pathol. 1999;188(2):119-125.

6. Woertler K, Lindner N, Gosheger G, Brinkschmidt C, Heindel W. Osteochondroma: MR imaging of tumor-related complications. Eur Radiol. 2000;10(5):832-840.

7. Stieber JR, Pierz KA, Dormans JP. Hereditary multiple exostoses: a current understanding of clinical and genetic advances. Univ $P A$ Orthop J. 2001;14:39-48.

8. Mordenti M, Ferrari E, Pedrini E, et al. Validation of a new multiple osteochondromas classification through Switching Neural Networks. Am J Med Genet A. 2013;161(3):556-560.

9. Brien EW, Mirra JM, Kerr R. Benign and malignant cartilage tumors of bone and joint: their anatomic and theoretical basis with an emphasis on radiology, pathology and clinical biology. I. The intramedullary cartilage tumors. Skeletal Radiol. 1997;26(6):325-353.

10. Albrecht S, Crutchfield JS, SeGall GK. On spinal osteochondromas. J Neurosurg. 1992;77(2):247-252.

11. Roblot P, Alcalay M, Cazenave-Roblot F, Levy P, Bontoux D. Osteochondroma of the thoracic spine. Report of a case and review of the literature. Spine (Phila Pa 1976). 1990;15(3):240-243.

12. Pierz KA, Womer RB, Dormans JP. Pediatric bone tumors: osteosarcoma ewing's sarcoma, and chondrosarcoma associated with multiple hereditary osteochondromatosis. J Pediatr Orthop. 2001;21(3): 412-418.

13. Wirganowicz PZ, Watts HG. Surgical risk for elective excision of benign exostoses. J Pediatr Orthop. 1997;17(4):455-459.

14. Yanagawa T, Watanabe H, Shinozaki T, Ahmed AR, Shirakura K, Takagishi $\mathrm{K}$. The natural history of disappearing bone tumours and tumour-like conditions. Clin Radiol. 2001;56(11):877-886.

15. Bell MS. Benign cartilaginous tumors of the spine. A report of one case together with a review of the literature. Br J Surg. 1971;58(9): 707-711. 
16. Loftus CM, Rozario RA, Prager R, Scott RM. Solitary osteochondroma of T4 with thoracic cord compression. Surg Neurol. 1980;13(5):355-357.

17. Sakai D, Mochida J, Toh E, Nomura T. Spinal osteochondromas in middle-aged to elderly patients. Spine (Phila Pa 1976). 2002;27(23): E503-E506.

18. Saifuddin A, White J, Sherazi Z, Shaikh MI, Natali C, Ransford AO. Osteoid osteoma and osteoblastoma of the spine. Factors associated with the presence of scoliosis. Spine (Phila Pa 1976). 1998;23(1):47-53.

19. Khosla A, Martin DS, Awwad EE. The solitary intraspinal vertebra osteochondroma. An unusual cause of compressive myelopathy: features and literature review. Spine (Phila Pa 1976). 1999;24(1):77-81.

20. Dahlin D. Bone Tumors: General Aspects and Data on 6221 Cases. 3rd ed. Springfield IL: Charles G. Thomas; 1978.

21. Ratliff J, Voorhies R. Osteochondroma of the C5 lamina with cord compression: case report and review of the literature. Spine (Phila Pa 1976). 2000;25(10):1293-1295.

22. Glasauer FE. Benign lesions of the cervical spine. Acta Neurochir (Wien). 1978;42:161-175.

23. Kim FM, Poussaint TY, Barnes PD. Neuroimaging of scoliosis in childhood. Neuroimaging Clin N Am. 1999;9(1):195-221.
24. Malat J, Virapongse C, Levine A. Solitary osteochondroma of the spine. Spine (Phila Pa 1976). 1986;11(6):625-628.

25. Sharma MC, Arora R, Deol PS, Mahapatra AK, Mehta VS, Sarkar C Osteochondroma of the spine: an enigmatic tumor of the spinal cord. A series of 10 cases. J Neurosurg Sci. 2002;46(2):66-70.

26. Mikawa Y, Watanabe R, Nakashima Y, Hayashida T. Cervical spinal cord compression in hereditary multiple exostoses. Report of a case and a review of the literature. Arch Orthop Trauma Surg. 1997;116(1-2):112-115.

27. Bhojrai SY, Panjwani JS. A new management approach to decompression, posterior stabilization, and fusion for cervical laminar exostosis with cord compression in a case of diaphyseal aclasis: Case report and review of the literature. Spine (Phila Pa 1976). 1993;18(10): 1376-1379.

28. Labram EK, Mohan J. Diaphyseal aclasis with spinal cord compression. Report of two cases and review of the literature. J Neurosurg. 1996;84(3):518-521.

29. Rao H, Jakheria S. Giant cervical exostosis: a case report with review of literature. J Pediatr Orthop B. 2009;18(2):103-105.
Orthopedic Research and Reviews

\section{Publish your work in this journal}

Orthopedic Research and Reviews is an international, peer-reviewed, open access journal focusing on the patho-physiology of the musculoskeletal system, trauma, surgery and other corrective interventions to restore mobility and function. Advances in new technologies, materials, techniques and pharmacological agents are particularly welcome. The journal welcomes

\section{Dovepress}

original research, clinical studies, reviews \& evaluations, expert opinion and commentary, case reports and extended reports. The manuscript management system is completely online and includes a very quick and fair peer-review system, which is all easy to use. Visit http://www.dovepress. com/testimonials.php to read real quotes from published authors.

Submit your manuscript here: http://www.dovepress.com/orthopedic-research-and-reviews-journal 